\title{
Vitamin D deficiency in healthy people and its relationship with gender and age
}

\author{
Zaher Khazaei $^{1}$, Salman Khazaei ${ }^{2}$, Sara Beigrezaei $^{3}$, Hamid Nasri $^{3 *}$
}

\begin{abstract}
Introduction: Vitamin D is a fat-soluble steroid prohormone. Vitamin D is an important regulator of calcium absorption and bone growth.

Objectives: There is considerable controversy and conflicting studies on relationship between serum vitamin D in healthy individuals and ageing. The aim of this study is to test the relationship between serum 25 -hydroxyvitamin vitamin $\mathrm{D}$ with age groups and gender in a group of Iranian healthy individuals.

Patients and Methods: In this current cross-sectional study, 102 healthy individuals were selected. Serum vitamin D levels were measured using ELISA kit. According to the history and laboratory tests, patients with the history of diabetes, any active or chronic infections, liver disease, diabetes or malignancy were excluded from the study. Any history of administration of vitamin D was also an exclusion criterion. All participants had normal renal function detected by normal serum creatinine and blood urea nitrogen (BUN). To determine the relationship between gender (two categories) and age group (three categories) with vitamin D levels, Mann-Whitney $U$ and Kruskal-Wallis tests were used respectively.

Results: The average age of the participants was $42.97 \pm 15.54$ years. The mean vitamin D level was $17.32 \pm 12.16 \mathrm{ng} / \mathrm{mL}$. In this study, $73 \%$ of individuals had vitamin D deficiency, $18 \%$ had marginal deficiency and $9 \%$ had a normal vitamin D levels. This study showed a significant relationship between vitamin $\mathrm{D}$ and age of subjects $(r=0.23, P=0.02)$.

Conclusion: High percentage of vitamin D deficiency in the participants of our study requires more attention to this public health entity. A direct relationship between serum vitamin $\mathrm{D}$ level and the age of healthy individuals requires further investigation.

Keyword: Vitamin D, Deficiency, Gender, Age, Healthy

Please cite this paper as: Khazaei Z, Khazaei S. Beigrezaei S, Nasri H. Vitamin D deficiency in healthy people and its relationship with gender and age. J Parathyr Dis. 2018;6(1):16-18. DOI: 10.15171/jpd.2018.06.

Copyright (c) 2018 The Author(s); Published by Nickan Research Institute. This is an open-access article distributed under the terms of the Creative Commons Attribution License, which permits unrestricted use, distribution, and reproduction in any medium, provided the original work is properly cited.
\end{abstract}

\section{Introduction}

Vitamin $\mathrm{D}$ is a fat-soluble steroid prohormone and is formed when the skin is exposed to the ultra-violet radiation. The molecule of 7-dehydrocholesterol presents in skin and absorbs the UV radiation to produce cholecalciferol and then transfers it to the liver. As it is turned into 25-hydroxyvitamin vitamin $\mathrm{D}$ in the liver, it is released into the blood and reaches to the kidneys. After applying the effects of 1-alpha-hydroxylase, it turns unto 1,25-dihydroxyvitamin D3 (1). Around 90\% of necessary vitamin $\mathrm{D}$ for the body is provided as a consequence of UV exposure while $10 \%$ of it is obtained from food (1). Vitamin D is an important regulator of calcium absorption and bone growth and plays an important role in calcium hemostasis. There are exclusive receptors for 25-hydroxyvitamin D in bones and gastrointestinal system (2). Vitamin D plays an important role in preventing some types of diseases such as colon and prostate cancers, osteoporosis and diabetes type 1 (1-3). It is also interacted in chronic obesity-related diseases such as cardiovascular diseases, hypertension and mellitus diabetes $(2,3)$.

Vitamin D deficiency is diagnosed with its level lower than $20 \mathrm{mg} / \mathrm{mL}$ in blood. Its marginal deficiency is the range of 21 to $29 \mathrm{mg} / \mathrm{mL}$. Normal vitamin D level is more than 30 $\mathrm{mg} / \mathrm{mL}$ (1). Vitamin D deficiency is due to low vitamin D intake through foods, low exposure to sunlight, vitamin $\mathrm{D}$ mal absorption in the intestine and perturbations regarding the buildup of vitamin $\mathrm{D}$ final product in the liver or the kidney. Other risk factors including having dark skin color, winter, living in a location with high geographical latitude, using sunscreens, exposure to air pollution, clouds or fog (2-4).

\section{Objectives}

There are considerable controversy and conflicting studies on the relationship between vitamin $\mathrm{D}$ levels in healthy individuals with ageing. The aim of the current study is to investigate the relation between serum 25 -hydroxyvitamin 
Implication for health policy/practice/research/ medical education

In a study on 102 healthy participants, we found a significant relationship of vitamin D with age of subjects $(r=0.23$, $P=0.02$ ). We also found, $73 \%$ of individuals had vitamin D deficiency, $18 \%$ had marginal deficiency and $9 \%$ had a normal vitamin D levels. High percentage of vitamin D deficiency in the participants of our study requires more attention to this public health entity. A direct relationship between serum vitamin $\mathrm{D}$ level and the age of healthy individuals requires further investigation.

D with age groups and gender in a group of Iranian healthy individuals.

\section{Patients and Methods}

\section{Study population}

In the current cross-sectional study, 102 healthy individuals were participated. According to the history and laboratory tests, patients with the history of diabetes, any active or chronic infections, liver disease or malignancy were excluded from the study. Any history of administration of vitamin D was also an exclusion criterion. Around 102 healthy participants were included to the study. All patients had normal renal function by normal serum creatinine and blood urea nitrogen (BUN).

\section{Vitamin D assessment}

Serum vitamin D levels were measured using DRG ELISA kit (USA). In this study, having a vitamin D level of lower than $20 \mathrm{ng} / \mathrm{mL}$ was considered as vitamin D deficiency. Levels of 20.1 to $29.9 \mathrm{ng} / \mathrm{mL}$, interpreted as marginal deficiency and higher than $30 \mathrm{mg} / \mathrm{mL}$ were considered as normal vitamin D levels.

\section{Ethical issues}

The research followed the tenets of the Declaration of Helsinki. Written informed consent was obtained from all patients. This study was approved by Ethical Committee of Nickan Research Institute.

\section{Statistical analysis}

Descriptive analysis including frequency table, mean and standard deviation (SD) were used for introducing and describing data. According to the absence of normality assumption for variables, we applied non-parametric Mann-Whitney U and Kruskal-Wallis tests, to determine the relationship between gender variable (two categories) and age group (three categories) with levels of vitamin $D$ respectively. Data were analyzed using SPSS software version 16 and $P<0.05$ was assumed to be significant.

\section{Results}

Out of 102 healthy participants, 45 (44.1\%) of them were male and 57 (55.9\%) were female. The mean age of the participants was $42.97 \pm 15.54$ years. The average vitamin D level was $17.32 \pm 12.16 \mathrm{ng} / \mathrm{mL}$. The proportion of vitamin $\mathrm{D}$ deficiency, marginal vitamin $\mathrm{D}$ deficiency and normal vitamin D level were around $73 \%, 18 \%$ and $9 \%$ respectively.

According to Table 1, no significant relationship of serum vitamin $\mathrm{D}$ level with participants' gender was detected $(P=0.66)$.

Around 68 (66.67\%) of participations were in 30-60 age group range. Serum vitamin D levels according to the age group of participations were shown in Table 2.

In this study we found a significant relationship between vitamin D and age of subjects $(r=0.229, P=0.02$; Figure 1$)$.

\section{Discussion}

In the current study, the relationship between the serum vitamin D level of healthy individuals with their gender and also their age groups (the young, the adult and the elderly group) was investigated. The deficiency level of vitamin D in our subjects was $73 \%$. As the results showed, the vitamin $\mathrm{D}$ level of the healthy individuals had no relationship with their gender. For different age groups, older participants had a higher serum vitamin D levels. The level in the adult group is significantly higher when

Table 1. Serum vitamin D levels according to the gender of healthy individuals

\begin{tabular}{llcc}
\hline Variable & & No. (\%) & Vitamin D level (ng/mL) \\
\hline \multirow{3}{*}{ Gender $^{\mathrm{a}}$} & Males & $45(44.1)$ & $17.35 \pm 11.6$ \\
& Females & $57(55.9)$ & $17.29 \pm 12.69$ \\
& Total & 102 & $17.32 \pm 12.16$ \\
\hline
\end{tabular}

${ }^{\mathrm{a}} P=0.66$.

Table 2. Serum vitamin D levels according to the age group of healthy individuals

\begin{tabular}{llcc}
\hline Variable & & No. (\%) & Vitamin D level (ng/mL) \\
\hline \multirow{3}{*}{ Age group } & $30-60$ & $23(22.54)$ & $12.1 \pm 95.23$ \\
$(y)^{a}$ & $>60$ & $11(10.78)$ & $18.13 \pm 80.39$ \\
& Total & 102 & $17.8 \pm 86.05$ \\
& &
\end{tabular}

a $P=0.023$

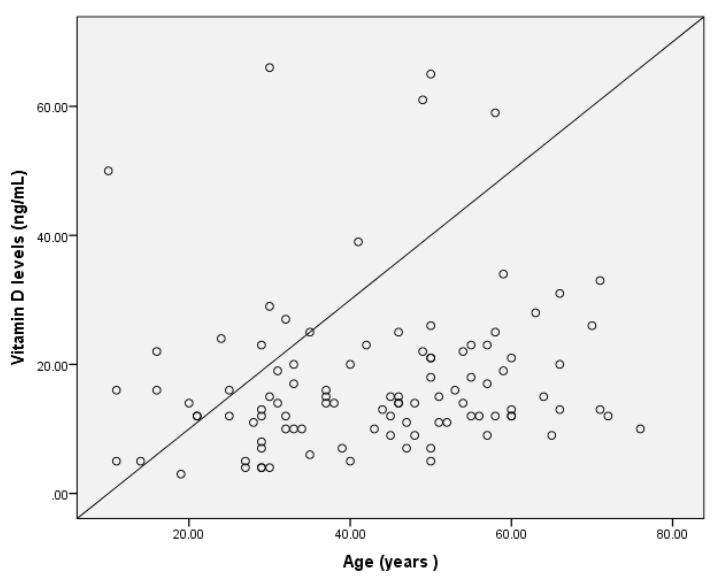

Figure 1. Significant relationship of vitamin D with age of subjects $(r=0.23, P=0.02)$. 
compared with the young age group. This study also showed a significant relationship of vitamin $\mathrm{D}$ with age of subjects $(r=0.23, P=0.02)$ by Spearman's rho test.

In line with our study, Steingrimsdottir et al found serum 25 dihydroxy-vitamin D levels in the older age groups were higher when compared with the adults (4). Similarly, no relationship between healthy individuals' gender and their vitamin D level was detected by Baradaran et al (5). Likewise, a significant relationship of serum vitamin D levels with age of the participants was detected too (5). Accordingly, Bischof-Ferrari et al found a positive relationship between serum 25-hydroxyvitamin D levels and age of participants (6). However, in the study of Adami et al, the association of low 25-hydroxyvitamin D level was not significantly related to participants' age. This finding is not consistent with above-mentioned studies and our investigation (7). Similar to our study, Kafeshani et al detected no relationship between serum vitamin D levels of the healthy individuals with their gender. They also found a relationship of vitamin D level and their age (8).

\section{Conclusion}

The high percentage of vitamin D deficiency in the participants in our study is clearly observable. Numerous factors may affect serum vitamin D level of the people, such as the exposure to sunlight, skin thickness and color, obesity, air pollution and different seasons of the year. It is possible that high proportion of vitamin $\mathrm{D}$ deficiency in our study is due to the fact that this research has been conducted in winter. This study also has been conducted in Isfahan and this city is among the most air polluted cities in the world. Air pollution is also responsible for vitamin $\mathrm{D}$ deficiency. It seems that more studies are necessary in different seasons and cities, to reach more confident conclusions.

\section{Limitations of the study}

Proportion of subjects in this study was relatively small. Therefore, it did not have enough power to show any significant relationships between variables. We suggest larger studies of this aspect of public health.

\section{Authors' contribution}

$\mathrm{HN}$ gathered the cases and conducted the research and selected the patients. Statistical analysis was conducted by ZK and SK. SBR prepared the primary draft. ZK and SK revised and edited the manuscript. HN prepared the final paper. All authors read and signed the final paper.

\section{Conflicts of interest}

The authors would like to declare that SBR and HN are the current staffs of the journal. The peer-review process of the current article has been performed in accordance with the COPE guidelines. SK and ZK had not any conflict of interest to declare.

\section{Ethical consideration}

Ethical issues (including plagiarism, data fabrication, double publication) have been completely observed by the authors.

Funding/Support

None.

\section{References}

1. Rawal G, Yadav S, Shokeen P. Health and the vitamin D. Int J Health Sci Res. 2015;5:416-23.

2. Holick MF. Vitamin D: importance in the prevention of cancers, type 1diabetes, heart disease, and osteoporosis. Am J Clin Nutr. 2004;79: 362-371.

3. Kim SH, Oh MK, Namgung R, Park MJ. Prevalence of 25-hydroxyvitamin D deficiency in Korean adolescents: association with age, season and parental vitamin D status. Public Health Nutr. 2014;17:122-30. doi: 10.1017/ S1368980012004703.

4. Steingrimsdottir L, Gunnarsson O, Indridason OS, Franzson L, Sigurdsson G. Relationship between serum parathyroid hormone levels, vitamin D sufficiency, and calcium intake. JAMA. 2005;294:2336-41. doi: 10.1001/ jama.294.18.2336.

5. Baradaran A, Behradmanesh S, Nasri H. Association of body mass index and serum vitamin D level in healthy Iranian adolescents. Endokrynol Pol. 2012;63:29-33.

6. Bischoff-Ferrari H, Borchers M, Gudat F, Dürmüller U, Stähelin H, Dick W. Vitamin D receptor expression in human muscle tissue decreases with age. J Bone Miner Res. 2004;19:265-9.

7. Adami S, Viapiana O, Gatti D, Idolazzi L, Rossini M. Relationship between serum parathyroid hormone, vitamin D sufficiency, age, and calcium intake. Bone. 2008;42:26770. doi: 10.1016/j.bone.2007.10.003.

8. Kafeshani M, Zarafshani M, Shokri-Moghaddam S, Ahmadi A, Nasri H. Serum 25-hydroxy vitamin D level in diabetic patients versus normal individuals; a pilot study. J Parathyr Dis. 2016;4:40-43. 